\title{
Considering HIV Risk and Intimate Partner Violence Among Older Women of Color: A Descriptive Analysis
}

\author{
Mary Sormanti, PhD \\ Elwin $\mathrm{Wu}, \mathrm{PhD}$ \\ Nabila El-Bassel, DSW, MSW
}

\begin{abstract}
This study describes the types of intimate partner violence (IPV) and sexual HIV-risk factors reported by a sample of 139 African American and Latina women ages 50 and older receiving care in outpatient clinics of an urban medical center. Additionally, we obtained estimates of the associations between experiencing IPV in a primary heterosexual relationship and the following HIV-risk behaviors among our sample of older minority women: (a) having multiple sexual partners, (b) STD history, (c) partner-related risk (i.e., having a partner who has multiple sexual partners, is HIV-infected, injecting drugs, and/or has an STD), and (d) self-perception of risk for HIV infection. Results indicate that many of these women are engaged in sexual risk behaviors, and such
\end{abstract}

The authors are affiliated with the Center for Intervention and Prevention Research in HIV and Drug Abuse at the Columbia University School of Social Work. Mary Sormanti is Associate Professor at Columbia University School of Social Work; Elwin $\mathrm{Wu}$ is Director of Operations at the Center for Intervention and Prevention Research in HIV and Drug Abuse; Nabila El-Bassel is Associate Professor at the Columbia University School of Social Work and Director at the Center for Intervention and Prevention Research in HIV and Drug Abuse.

Address correspondence to: Dr. Mary Sormanti, Associate Professor, Columbia University School of Social Work, 622 West 113th Street, New York, NY 10025 (E-mail: ms778@columbia.edu).

This study was supported by NIMH grant \#MH57145 awarded to Dr. El-Bassel.

Women \& Health, Vol. 39(1) 2004

http://www.haworthpress.com/store/product.asp?sku=J013

(C) 2004 by The Haworth Press, Inc. All rights reserved.

Digital Object Identifier: 10.1300/J013v39n01_03 
behaviors are associated with increased likelihood of IPV for this cohort. Implications for health care professionals are discussed. [Article copies available for a fee from The Haworth Document Delivery Service: 1-800-HAWORTH. E-mail address: <docdelivery@haworthpress.com> Website: <http://www.HaworthPress.com> () 2004 by The Haworth Press, Inc. All rights reserved.]

KEYWORDS. HIV/AIDS, intimate partner violence, aging, women, health, sexuality

\section{INTRODUCTION}

A substantial body of research has established that two of the most significant public health issues-intimate partner violence (IPV) and HIV-are linked for many women. A number of sexual and drug-related HIV-risk factors including unprotected sex (Amaro 1995; Cunningham et al. 1994; Wingood and DiClemente 1997); inability to negotiate condom use (Fischbach and Herbert 1997); sex with an HIV positive partner or multiple partners (Cohen et al. 2000; Cunningham et al. 1994; El-Bassel et al. 1999; Van der Straten et al. 1995); trading sex for drugs, money, or shelter (Cohen et al. 2000); forced needle sharing (El-Bassel et al. 2000); gynecologic problems including STDs, urinary tract infections, and pelvic inflammatory disease (Plichta and Abraham 1996); disclosure of STDs or HIV seropositivity (El-Bassel et al. 1999; Rothenberg and Paskey 1995); and insistence upon male or female condom use (El-Bassel et al. 2000) have been associated with abuse of women. Numerous studies also provide evidence that HIV-risk is associated with fear of IPV (Basile, 1999; Quina et al. 1997; Wingood and DiClemente 1997). Research on the interface between these public health epidemics, however, has been limited primarily to women younger than 50, even though their older counterparts also negotiate both problems (i.e., IPV and HIV-risk). Consequently, although the evolving body of literature on younger adults is informative, it neither accurately reflects the incidence or prevalence of these health problems for older women nor provides sufficient data for understanding how HIV risk and IPV conjointly affect this vulnerable cohort. The present study addresses this gap by describing the types of IPV and sexual HIV-risk factors reported by a sample of older minority women recruited from an urban medical center and the associations between these complex public health problems. 


\section{HIV and Older Women}

Women ages 50 and older with HIV/AIDS are an overlooked population who represent a major public health concern (Tabnack and Sun 2000; Wutoh et al. 1998). Although the overall incidence of AIDS in the United States has been declining since 1996, new cases of HIV/AIDS in the age 50 and older population are increasing, especially among minorities (Brown and Sankar 1998; Tabnack and Sun 2000; Zablotsky 1998) and women (Ory, Zablotsky and Crystal 1998). Frequently reported to account for $10 \%$ of the cumulative AIDS caseload, some believe the actual percentage for this cohort is higher (Ory and Mack 1998; Stall and Catania 1994; Zablotsky 1998). Currently, more than 86,000 people ages 50 and older have been diagnosed with AIDS and 8,800 have been diagnosed with HIV (CDC 2002). Through June 2001, women account for more than $15 \%$ and $25 \%$, respectively, of these groups (CDC 2002).

While sexual activity tends to decline with age, large numbers of women and men continue to be sexually active in their 70s and 80s (Diokno, Brown and Herzog 1990). Very little information, however, is available on sexual risk behaviors among older adults, especially African Americans and Latinos (Brown and Sankar 1998; Levy 1998; Ory and Mack 1998). While older adults have the same risk factors for HIV transmission as younger patients (Finestone 1993; Gaeta, LaPolla and Melendez 1996), older persons with AIDS are much more likely than younger adults to have an undetermined exposure category, resulting in a considerable gap in the current understanding about their routes of transmission (O'Leary and Wingood 2000; Vogler, Dugan and Seidlin 1989). In addition, many physicians continue to overlook the possibility of HIV/AIDS in this cohort (Finestone 1993; Stall and Catania 1994), primary prevention education efforts have been notably lacking for the 50 and older population (Linsk 2000; Ory, Zablotsky and Crystal 1998; Strombeck and Levy 1998) and researchers, whose agendas may reflect a common misperception that older persons rarely, if ever, engage in drug and sexual risk behaviors, have not sufficiently examined their risk-taking behaviors (Richard, Bell and Montoya 2000; Stall and Catania 1994).

Moreover, although the HIV risk profile for older women is incomplete (Levy 1998; Schable, Chu and Diaz 1996; Stall and Catania 1994; Zablotsky 1998), several factors may increase their vulnerability to HIV. These include: (a) normative biological changes related to aging such as decreases in antibody production (Crisologo, Campbell and Forte 1996; Levy 1998); (b) post-menopausal changes such as thinning 
of the vaginal wall and decreased lubrication (Gaeta, LaPolla and Melendez 1996; Zablotsky 1998); (c) lower levels of knowledge about HIV transmission, symptomatology, and proper condom usage than younger women (Zablotsky 1998); (d) fertility status (Semaan, Lauby and Walls 1997); (e) diminished likelihood of condom use and HIV testing (Crisologo, Campbell and Forte 1996; Gaeta, LaPolla and Melendez 1996; Kaye and Markus 1997; Ory and Mack 1998); (f) inadequate preparation for negotiation of safer sex practices secondary to traditional gender inequities (Levy 1998; Ory and Mack 1998); (g) increased difficulty in discussing HIV-related concerns with health professionals (Siegal and Burke 1997); and (h) inadequate sexual communication skills (Strombeck and Levy 1998). Comorbidity is also pervasive among older adults with HIV/AIDS and complicates the processes of diagnosis, treatment, and coping (Gaeta, LaPolla and Melendez 1996; Ory, Zablotsky and Crystal 1998). Finally, the health care system's slow acceptance of the presence of HIV/AIDS in older women also contributes to these complications, resulting in misattribution of HIV-related symptomatology to normative conditions of aging, delayed diagnoses, and inadequate treatment (Cohan and Atwood 1994; Tabnack and Sun 2000).

\section{Intimate Partner Violence Perpetrated Against Older Women}

Very few studies have investigated prevalence rates of IPV in older women. It has been suggested that this dearth of information is one result of an ageist and sexist health care system that renders older women invisible despite their growing numbers (Kaveny 1998; McCandless and Conner 1999; Vinton 1991). Consequently, although IPV occurs throughout the life course, older abused women have been largely overlooked, and the characteristics and circumstances of their experiences with violent partners remain under-explored (Brandl and Raymond 1997; Harris 1996; Ramsey-Klawsnik 1991; Schaffer 1999; Seaver 1996; Vinton 1991; Wolkenstein and Sterman 1998).

In addition, few studies have attempted to develop a profile of the typical older abuse victim or perpetrator, and those in existence have been based on majority samples (Griffin, Williams and Reed 1998; Penhale 1999), resulting in even more limited knowledge about the experiences of abused older women from diverse ethnic and cultural groups. Long-held assumptions about the abuse of older women portrayed victims as frail and dependent care-recipients of abusers who were well intentioned, overburdened caregivers. Recent data does not 
support this theory, but rather suggests that abused older women are generally well-functioning victims of socioemotionally unstable relatives who are dependent upon them (Penhale 1999; Pillemer and Finkelhor 1989). Furthermore, these abusers are likely to be spouses. Seaver (1996) found that in a sample of 132 women ages 53 to 90 years old seeking elder abuse services, fifty-eight percent of their abusers were husbands. Vinton (1992) found that of 132 women ages 60 and older receiving shelter services, the vast majority of their abusers were spouses. Another investigation of women over the age of 65 receiving protective elder care services revealed that nearly one-third were sexually abused by their male partners (Ramsey-Klawsnik 1991). Older women are also victims of marital rape (Peacock 1998; Seaver 1996) and acquiesce to unwanted sex in marital and long-term intimate relationships as a strategy of avoiding potential and real physical danger from the partner (Basile 1999).

Given the increase of HIV and sexual risk behavior among older women and data showing that IPV is a risk factor for sexual risk behaviors, investigations of the interplay between these issues for older women is critical. This study describes the types of IPV and sexual HIV-risk factors reported by a sample of 139 African American and Latina women ages 50 and older receiving care in outpatient clinics of an urban medical center and provides estimates of the associations between experiencing IPV in a primary heterosexual relationship and the following HIV-risk indicators: (a) having multiple sexual partners, (b) STD history, (c) partner-related risk (i.e., having a partner who has multiple sexual partners, is HIV-infected, injecting drugs, and/or has an STD), and (d) self-perception of risk for HIV infection.

\section{METHODS}

\section{Recruitment}

As part of a larger investigation of a relationship-focused STD/HIV prevention intervention (El-Bassel et al. 2001; El-Bassel et al. in press), women patients age 18 and above were recruited from several primary health clinics of a large urban hospital in a predominantly low-income community in New York City. In some neighborhoods served by these outpatient clinics, the AIDS prevalence is two to three times higher than in New York City as a whole (New York City Department of Health 2000). The women patients were approached by female recruiters, pro- 
vided with a printed description of the study, and invited to complete a brief screening questionnaire to determine study eligibility. Although eligibility criteria for the larger parent study were established to insure inclusion of women at high risk for HIV and other STDs, the data presented in this paper are the responses of all women of color ages 50 and older who completed the screening instrument regardless of their qualification for the parent study. (Because only one woman in this age cohort self-identified as white, she was dropped from the present analyses.) In addition to a minimum age of 18 years and outpatient clinic patient status, all of the women whose data will be described here reported current involvement with a man whom they identified as a "spouse, lover or boyfriend" (herein referred to as the primary partner). Participants were given a subway pass valued at $\$ 3$ as recompense for completion of the screening. This research was approved by institutional review boards at the university and the hospital, which oversee human participation in research.

\section{Measurement}

Demographics: Sociodemographic data included age, race/ethnicity, employment status, current relationship status, and length of relationship with the primary partner. The latter variable was coded as a dichotomous variable (i.e., more or less than six months in duration).

Intimate Partner Violence (IPV): IPV was measured with a series of six items derived from the Revised Conflict Tactics Scale (Straus et al. 1996) that denote differing levels and types of abuse. Moderate physical IPV was determined by a positive response to at least one of the following two items: "partner twisted your arm or hair, or threw something at you that could hurt" and "partner pushed, grabbed or slapped you." Severe physical IPV was indicated by a positive response to any of the following three items: "partner kicked you or slammed you against a wall, punched or hit you with something that could hurt you," "partner beat you up, or burned or scalded you on purpose," and "partner choked you, or used a knife or gun on you." Sexual violence was measured by a woman's positive response to one item: "partner used force (like hitting, holding you down or using a weapon) to make you have sex." Respondents also indicated the time period in which these situations had occurred. "Current" IPV was operationalized according to two criteria: (a) a positive response to at least one of the IPV screening questions, and (b) at least one of these responses indicates that the abuse occurred within the past six months. "Lifetime" IPV was operationalized in the 
same manner except that none of the abuse occurred in the preceding six months.

HIV Risk: HIV risk was measured with a series of items that were worded to focus specifically on the participant and her self-identified primary partner. Sex-related HIV risk behaviors were measured with selected items from the Sexual Risk Behavior Questionnaire (SRBQ). The SRBQ has been implemented with more than 1,500 female and male participants recruited from a range of settings, including drug treatment centers, STD clinics, primary healthcare and emergency departments (El-Bassel et al. 2001; Gilbert et al. 2000). The selected items include: (a) number of sexual partners in the preceding year, (b) history of having an STD, and (c) condom use consistency during instances of sex with the primary partner during the preceding three months. Additionally, respondents were asked whether they knew or suspected that their primary partners met at least one of the following sex- or drug-related HIV risk criteria: (a) had sex with other men or women in the last 90 days, (b) had contracted or exhibited symptoms of an STD in the last 90 days, (c) had injected drugs in the last 90 days, or (d) was HIV positive.

Perception of HIV Risk: Perceived HIV risk was assessed with one question: "How worried are you that you might already have or may in the future get HIV, the virus that causes AIDS?" Respondents were asked to choose from the following: "not at all worried," "a little worried," "somewhat worried," and "very worried."

\section{Data Analysis}

T-tests, one-way ANOVA, chi-square, and binary logistic regression analyses were conducted to examine bivariate associations among demographic, HIV, and IPV variables. Where applicable we report odds ratios (ORs) and their 95\% confidence intervals (CIs). Due to the low frequency of reports of condom use consistency other than "never use condoms," we were unable to estimate reliable ORs for this variable. Estimates with p values smaller than .05 (or 95\% CIs that do not include 1.0) were deemed significant.

\section{RESULTS}

\section{Sociodemographics}

Participants ranged in age from 50 to 83 , with a mean of 55 years $(\mathrm{SD}=5.3$ years). More than half of the women identified as Latina and 
44\% identified as African American. The bulk of the participants did not work for pay during the month prior to the interview. More than one-third of the women were divorced or separated, one-third were married, less than 20\% identified as never married, and more than $10 \%$ identified as widowed. All but five of these women (96\%) indicated that the duration of their relationships with their primary partners was at least six months (see Table 1).

\section{HIV Risk}

Table 2 presents summary data on HIV sexual risk factors among the study sample. Most of these women were sexually active; eighty percent reported having had sexual intercourse within the past 90 days. About 3\% of the women reported being HIV positive. Approximately $15 \%$ of the participants had more than one sexual partner during the previous year. About one-quarter of the participants reported currently having an STD or having had one in the past. The large majority of women $(86.3 \%)$ reported never using condoms during sexual intercourse with their primary partners throughout the preceding three months; less than $6 \%$ reported using a condom during every occurrence of intercourse with their primary partners within that same time period. The remaining women $(8.9 \%)$ reported using condoms during some acts of

TABLE 1. Sociodemographic Characteristics of the Study Sample $(N=139)$

\begin{tabular}{|c|c|c|}
\hline & $\mathrm{n}$ & $\%$ \\
\hline Age (years) & $\begin{array}{c}\text { Mean }=55.0 \\
S D=5.3\end{array}$ & \\
\hline \multicolumn{3}{|l|}{ Race/ethnicity } \\
\hline Latina & 78 & 56.1 \\
\hline African American & 61 & 43.9 \\
\hline Unemployed & 108 & 77.7 \\
\hline \multicolumn{3}{|l|}{ Marital status } \\
\hline Married & 45 & 32.4 \\
\hline Single, never married & 26 & 18.7 \\
\hline Separated or divorced & 50 & 36.0 \\
\hline Widowed & 18 & 12.9 \\
\hline \multicolumn{3}{|l|}{ Length of relationship } \\
\hline$\leq 6$ months & 5 & 3.6 \\
\hline$>6$ months & 134 & 96.4 \\
\hline
\end{tabular}


TABLE 2. Sexual HIV Risk Factors and Perception of Risk ( $=139)$

\begin{tabular}{|c|c|c|}
\hline & $\mathrm{n}$ & $\%$ \\
\hline$>1$ partner in last year & 20 & 14.4 \\
\hline Have/had an STD & 36 & 25.9 \\
\hline HIV-positive & 4 & 2.9 \\
\hline \multicolumn{3}{|l|}{ Condom use consistencya } \\
\hline Every time & 8 & 5.8 \\
\hline More than half of the time & 2 & 1.4 \\
\hline Half of the time & 4 & 2.9 \\
\hline Less than half of the time & 5 & 3.6 \\
\hline Never use condoms & 120 & 86.3 \\
\hline Primary partner with known HIV riskb & 20 & 14.4 \\
\hline \multicolumn{3}{|l|}{ Perception of HIV risk } \\
\hline Not at all worried & 62 & 44.6 \\
\hline A little worried & 24 & 17.3 \\
\hline Somewhat worried & 10 & 7.2 \\
\hline Very worried & 39 & 28.1 \\
\hline
\end{tabular}

a Women who reported not having sex with their partners during the previous six months $(n=28)$ were categorized as "Never use condoms."

b The percentage reflects the entire sample. Only 111 women answered this question (limited to those who had sex with partner during the previous 6 months).

penetrative sex with their primary partners in the past three months. Of those who were sexually active, more than one in ten women reported knowing that their primary partners placed them at risk for HIV transmission; slightly more than half of the women who reported being HIV-negative expressed at least some concern about becoming infected with the virus in the future.

On average, women who reported having multiple partners were significantly younger than women who did not have multiple partners $(\mathrm{t}(106)=-6.5, \mathrm{p}<.01)$. African Americans were more likely than Latinas to report having multiple partners $(\mathrm{OR}=4.8 ; 95 \% \mathrm{CI}=[1.6$, 14]) and more likely than Latinas to report having a history of an STD $(\mathrm{OR}=3.6 ; 95 \% \mathrm{CI}=[1.6,7.9])$. There appeared to be a significant relationship between marital status and having a partner with known HIV risks $\left(\chi^{2}=8.0, \mathrm{df}=3, \mathrm{~N}=111, \mathrm{p}=.05\right)$, with the data indicating that those who were married were less likely to report having a partner with known HIV risks. Compared to those in relationships of greater than six months duration, those in newer relationships (i.e., less than 6 months in 
duration) were more likely to report having multiple partners $(\mathrm{OR}=.10$; $95 \% \mathrm{CI}=[.02, .62])$.

\section{Intimate Partner Violence}

Data on the prevalence of IPV by type and severity are presented in Table 3. Approximately 13\% $(\mathrm{n}=18)$ of the sample reported moderate physical IPV by their primary partners; for about $8 \%(\mathrm{n}=11)$ of these women, the IPV was perpetrated within the preceding six months. Severe physical IPV was reported by almost $5 \%$ of the participants; of these women, more than half recounted that their primary partners perpetrated the severe physical IPV in the preceding six months. About $3 \%$ of the sample reported that they had been victims of sexual violence perpetrated by their primary partners; for three of these women the sexual IPV was perpetrated within the past six months. Race was the only sociodemographic factor significantly associated with IPV. Specifically, African Americans were more likely than Latinas to report lifetime IPV $(\mathrm{OR}=3.3 ; 95 \% \mathrm{CI}=[1.2,9.1])$ and more likely than Latinas to report current IPV $(\mathrm{OR}=4.5 ; 95 \% \mathrm{CI}=[1.2,17])$.

\section{Intimate Partner Violence and HIV Risk}

The associations between HIV risk and IPV are presented in Table 4. Compared to women who had one sexual partner within the past year,

TABLE 3. Women's Experiences of Intimate Partner Violence $(\mathrm{N}=139)$

\begin{tabular}{lcr} 
& $\mathrm{n}$ & $\%$ \\
\hline $\begin{array}{l}\text { Moderate physical abuse } \\
\quad \text { Currenta }\end{array}$ & 11 & 7.9 \\
Lifetime $^{\mathrm{b}}$ & 18 & 12.9 \\
Severe physical abuse & & \\
$\quad$ Current & 4 & 2.9 \\
$\quad$ Lifetime & 7 & 4.9 \\
Sexual abuse & & \\
$\quad$ Current & 3 & 2.2 \\
$\quad$ Lifetime & 4 & 2.9 \\
Any IPV & & \\
$\quad$ Current & 11 & 7.9 \\
$\quad$ Lifetime & 18 & 12.9 \\
\hline
\end{tabular}

a Current abuse occurred within the preceding six months.

b Lifetime abuse occurred within and before preceding six months. 
TABLE 4. Relationship Between Intimate Partner Violence (IPV) and HIV Risk

\begin{tabular}{|c|c|c|c|c|}
\hline \multirow[b]{2}{*}{ HIV Risk } & \multicolumn{2}{|c|}{ Lifetime IPV } & \multicolumn{2}{|c|}{ Current IPV } \\
\hline & OR & $95 \% \mathrm{Cl}$ & OR & $95 \% \mathrm{Cl}$ \\
\hline$>1$ partner in last year & 4.8 & $1.6,14.4$ & 8.2 & $2.3,29.3$ \\
\hline Have/had an STD & 1.4 & $.48,4.0$ & 1.5 & $.42,5.3$ \\
\hline $\begin{array}{l}\text { Primary partner with known } \\
\text { HIV risk }\end{array}$ & 3.9 & $1.3,11.9$ & 8.6 & $2.4,31.3$ \\
\hline $\begin{array}{l}\text { Perception of HIV riska } \\
\text { Not at all worried }\end{array}$ & & & & \\
\hline A little worried & 1.1 & $.27,4.8$ & 1.7 & $.27,11.2$ \\
\hline Somewhat worried & 3.4 & $.70,16.1$ & 5.2 & $.75,37.0$ \\
\hline Very worried & 1.2 & $.34, \quad 3.9$ & 2.2 & $.46,10.2$ \\
\hline
\end{tabular}

a Only women who were HIV-negative were included.

women with multiple sexual partners were significantly more likely to report lifetime IPV perpetrated by their primary partners. Similarly, women in relationships with partners with known HIV risk were more likely to report lifetime IPV perpetrated by their primary partners compared to women whose partners did not have known HIV risks.

When analyses were limited to comparisons between women who recounted current (i.e., within the past six months) IPV by their primary partners versus women who reported no incidents of IPV by their primary partners, the significant relationships noted above remained. The estimated OR for having more than one partner in the last year increased from 4.8 to 8.2, and the estimated OR for having a primary partner with know HIV risk increased from 3.9 to 8.6.

Finally, we recognized that the observed associations between HIV risk and IPV may be confounded by other observed (and unobserved) variables. For example, the association between race and self-reported HIV risk was noted earlier. Thus, additional analyses were conducted to examine the robustness of the associations between HIV risk and IPV. The significant associations between HIV risk and IPV noted above remained when analyses were conducted separately for African Americans and Latinas. When we controlled for sociodemographic variables during examination of the association between HIV risk and IPV, the patterns of significance remained, although the smaller number of women in certain "cells" (e.g., women who report current IPV) limits the utility of such multivariate analyses. 


\section{DISCUSSION}

To our knowledge, this is the first study to examine IPV and sexual HIV-risk behaviors among older women. The findings reveal that our sample of women over 50 is sexually active and that many are engaged in some sexual HIV risk behaviors. Moreover, our findings suggest that a history of abuse by a primary male partner is associated with increases in HIV-risk factors for this age cohort. Accordingly, this study strongly indicates that health care professionals and researchers must continue to confront long-held stereotypes about sexuality and HIV risk in later life if we are to truly confront the spread of the disease, especially among a vulnerable cohort in a geographical region with high prevalence of HIV infection. For example, although most of the sample was sexually active, that is, they report having sexual intercourse with their primary partners within the past three months, most also report that they never use condoms during sexual intercourse with these partners. Although this finding may not be surprising given that condom use among younger non-casual intimate partners also is low (Catania et al. 1994; Ickovics and Yoshikawa 1998; Misovich, Fisher and Fisher 1997) and older women and their partners no longer are concerned with unwanted pregnancy, the health consequences are unambiguous. More than a quarter of the sample reported having or having had a STD and a small number of women reported being HIV-positive. A minority also stated that they had additional sexual partners within the past 12 months. Furthermore, like their younger counterparts, the risk picture for these older women was more complicated than the use (or non-use) of condoms. Some of these women told us that they knew or believed that their primary male partner was engaged in either drug or sex-related HIV-risk behaviors. However, despite this recognition, many of the women stated that they were not at all worried about the possibility of becoming infected with HIV.

This sample's prevalence rates of lifetime and current abuse by a primary partner, although lower than those found among some younger samples, are sobering reminders that IPV is perpetrated by men (and experienced by women) across a wide range of psychosocial circumstances. Moreover, although care was taken to enhance the likelihood that women's reports would be accurate and honest (e.g., use of female Latina and African American recruiters who were closely trained and supervised), actual rates may be even higher than those reported. In addition, our findings highlight that older women who experience IPV are at elevated risk for HIV. In particular, these data indicate that having mul- 
tiple partners within the past year and/or having a primary partner who engaged in HIV-risk behaviors and/or was HIV-positive were the salient HIV-risk indicators associated with IPV among this sample of older women. When viewed within the context of the exceedingly low condom use consistency reported by this sample and recent findings by Wyatt et al. (2002) that demonstrate that HIV seropositivity is more likely among women of color with more sexual partners, these data are extremely concerning.

Our HIV risk data are consistent with recent increases in HIV/AIDS incidence among the 50 and older population and the notable lack of primary prevention education efforts for these groups (Linsk 2000; Ory et al. 1998; Strombeck and Levy 1998). The dearth of information about the sexual risk behaviors of older women may be both a reflection and a construction of individual-level and systemic factors. For example, health/mental health care systems generally do not explore adequately issues of sexuality with their older clients. In addition, many older adults may develop internal belief systems that minimize or "deny" their actual sexual risks (Linsk 2000). These factors likely interact with one another and together create a context of heightened vulnerability to HIV and STDs. From an epidemiological standpoint, it is imperative that researchers examine the extent of sexual risk behavior among this population to identify those sub-populations of older women and men at high risk.

Our data suggest that an intervention approach that begins by helping older women and their male partners to make an honest and realistic appraisal of their high risk sexual behaviors would be well worth exploring. Although recognition of one's risk alone is insufficient for changing risk behaviors, there is growing evidence to suggest that interventions that also incorporate cognitive and behavioral preparedness for risk reduction, including self-regulatory, communication, and negotiation skills, can be effective in helping individuals and couples to negotiate safer sex and thus reduce their risk for HIV transmission (El-Bassel et al. 2001a; Kelly et al. 1989). Furthermore, given that many health care professionals continue to ignore, overlook, and/or avoid the reality that older women engage in the same spectrum of behaviors and relationships that younger women do, changes to the service system and among service providers are also needed. For example, physicians, nurses, and others involved in the triage and medical treatment of older women must be trained to screen for HIV risk and IPV in this group and to help older women feel comfortable disclosing these sensitive issues. Simultaneously, primary prevention education programs and tools that nor- 
malize sexuality and empower older women to take positive steps to protect themselves from both HIV and IPV must be developed and disseminated. Such efforts would educate both patients and care providers and would be a significant improvement upon existing clinical models.

The data on IPV reported by this sample provide important information to guide the development of such HIV-prevention models for older women and indicate that these models may need to address the unique relationship issues of older women and their intimate partners. These findings substantiate earlier research that has found other populations of women with male partners who engaged in HIV-risk behaviors to be at higher risk for IPV than their counterparts (El-Bassel et al. 2001; Gilbert et al. 2000) and lends support to a body of research that has linked condom use with IPV (Harlow et al. 1993; Jemmott and Jemmott 1991; Quina et al. 1997; Wingood and DiClemente 1997).

Some have conjectured and/or found that male violence and/or fear of violence seriously undermines women's willingness and abilities to engage in HIV protective behaviors such as condom use and abstinence (Wyatt et al. 2002), thus increasing their risk of transmission. Others have suggested that violence may be an outcome of women's attempts to negotiate these protective behaviors (El-Bassel et al. 1999; Neighbors et al. 1996). Given the range of contexts and conditions within which women lead their lives, perhaps both of these scenarios are the reality for some women. Regardless of causality, the quandary that each situation reflects is both complicated and dangerous. Furthermore, because older women were underrepresented in these earlier studies, exactly how IPV and HIV risk are linked for them is especially unclear. Older women's experiences of partner violence may be qualitatively different from those of their younger counterparts. For example, they may face additional or different dynamics that hinder attempts to protect themselves (e.g., diminished social support, entrenched relational patterns, chronic medical conditions). The findings from this study call attention to the importance of dedicated studies with older women focusing on the relationship between HIV risk and IPV, or at the least, planned inclusion of older women in current and future research.

A larger sample size (or one that captured more variation with respect to HIV risk indicators) would allow for more efficient estimation of parameters related to the association between variables (e.g., ORs). Thus, implications of the statistics presented here should be derived from their direction and level of significance rather than from the exact value of the estimates. Furthermore, we recognize that this cross-sectional study does not enable us to test causal hypotheses (i.e., whether 
HIV risk leads to IPV or vice versa). We also are aware that the HIV-risk variables we analyzed may be collinear and that the separate analyses we used do not allow us to infer whether each of these variables represents a distinct HIV-risk factor or simply a single relationship measured multiple times. Future analyses based upon composite risk indices that better differentiate theoretically distinct domains of HIV risk are needed. Other study limitations include non-random sampling, which precludes us from generalizing our findings beyond the sample; and omission of a number of potentially important variables (e.g., woman's financial dependence on her male partner, male partner's substance use, woman's history of childhood trauma) that may confound the observed relationship between IPV and sexual HIV risk.

Overall, our findings contribute to the important body of work established by a relatively small but hopefully increasingly influential group of researchers, practitioners, and activists who believe that older women are a vulnerable population worthy of our most earnest attention and effort. We emphatically add our voices to those who have advocated for: (a) HIV/AIDS primary prevention efforts that are sensitive to the issues and needs of older adults, (b) exploration of older women's experiences in relationships, including abusive relationships, and (c) more research into the causal direction of the relationship between HIV risk and IPV for all women. Older women, who are especially vulnerable to HIV/ AIDS for a number of reasons (i.e., biological, social, and political), must be paid specific attention, whether or not they also are victims of IPV. Examination and exploration of a variety of issues critical to understanding HIV risk and IPV among older women is required. These include drug and sexual HIV-risk behaviors of women and their partners, childhood physical or sexual abuse history, history of IPV including onset and typologies, and other relational issues such as gender roles, expectations, and power differentials within the primary partnered relationship and the broader sociocultural context. Among older women who have experienced IPV, exploration into how IPV, fear of this violence, sexual coercion, demands to engage in unprotected sexual acts, and male sexual partners' responses if women either refuse to have unprotected sex or disclose having a STD-may be related to their abilities to negotiate safer sex practices with their primary partners-also would add considerably to our understanding of the links between these critical health issues. 


\section{REFERENCES}

Amaro, H. (1995). Love, sex, and power: Considering women's realities in HIV prevention. American Psychologist 50: 437-447.

Basile, K. (1999). Rape by acquiescence: The ways in which women "give in" to unwanted sex with their husbands. Violence Against Women, 5(9): 1036-1058.

Brandl, B., \& Raymond, J. (1997). Unrecognized elder abuse: Older abused women. Journal of Case Management 6(2): 62-68.

Brown, D., \& Sankar, A. (1998). HIV/AIDS and aging minority populations. Research on Aging 20(6): 865-884.

Catania, J., Coates, T., Golden, E., Dolcini, M., Peterson, J., Kegeles, S., Siegel, D., \& Fullilove, M. (1994). Correlates of condom use among black, hispanic and white heterosexuals in San Francisco: The AMEN longitudinal survey. AIDS Education \& Prevention 6: 12-26.

Centers for Disease Control and Prevention. (2002). HIV/AIDS Surveillance Report. Midyear edition, 13(1). Atlanta, GA: U.S. Department for Health and Human Services.

Cohan, N., \& Atwood, J. (1994). Women and AIDS: The social construction of gender and disease. Family Systems Medicine 12(1): 5-20.

Cohen, M., Deamant, C., Barkan, S., Richardson, J., Young, M., Holman, S., Anastos, K., Cohen, J., \& Melnick, S. (2000). Domestic violence and childhood sexual abuse in HIV-infected women and women at risk for HIV. American Journal of Public Health 90(4): 60-565.

Crisologo, S., Campbell, M., \& Forte, J. (1996). Social work, AIDS, and the elderly: Current knowledge and practice. Journal of Gerontological Social Work 26(1/2): 49-70.

Cunningham, R. M., Stiffman, A. R., Dore, P., \& Earls, F. (1994). The association of physical and sexual abuse with HIV risk behaviors in adolescence and young adulthood: Implications for public health. Child Abuse \& Neglect 18(3): 233-245.

Diokno, A., Brown, M., \& Herzog, A. (1990). Sexual function in the elderly. Archives of Internal Medicine 150(1): 197-200.

El-Bassel, N., Witte, S. S., Gilbert, L., Wu, E., Chang, M., Hill, J., \& Steinglass, P. (2003). The efficacy of a relationship based HIV/STD prevention program for heterosexual couples. American Journal of Public Health 93(6):963-969.

El-Bassel, N., Fontdevila, J., Gilbert, L., Voisin, D., Richman, B. L., and Pitchell, P. (2001). HIV risks of men in methadone maintenance treatment programs who abuse their intimate partners: A forgotten issue. Journal of Substance Abuse 13(2001): $1-15$.

El-Bassel, N., Witte, S.S., Gilbert, L., Sormanti, M., Moreno, C., Pereira, L., Elam, E., \& Steinglass, P. (2001a). HIV prevention for intimate couples: A relationshipbased model. Families, Systems and Health 19(4): 379-395.

El-Bassel, N., Gilbert, L., Rajah, V., Foleno, A., \& Frye, V. (2000). Fear and violence: Raising the HIV stakes. AIDS Education and Prevention 12(2): 154-170.

El-Bassel, N., Gilbert, L., Krishnan, S., Schilling, R. F., Gaeta, T., Purpura, S., \& Witte, S. S. (1999). Partner violence and sexual HIV-risk behaviors among women in an inner-city emergency department. Violence and Victims 13(4): 377-393. 
Finestone, A. (1993, July, 26-27.). Considering AIDS in the elderly. Pennsylvania Medicine.

Fischbach, R., \& Herbert, B. (1997). Domestic violence and mental health: Correlates and conundrums within and across cultures. Social Science Medicine 45(8): 1161-1176.

Gaeta, T., LaPolla, C., \& Melendez, E. (1996). AIDS in the elderly: New York City vital statistics. Journal of Emergency Medicine 14(1): 19-23.

Gilbert, L., El-Bassel, N., Schilling, R. F., Wada, T., \& Bennet, B. (2000). Partner violence and sexual HIV risk behaviors among women in methadone treatment. AIDS and Behavior 4(3): 261-269.

Griffin, L., Williams, O., \& Reed, J. (1998). Abuse of African American elders. In R. R.K. Bergen (Ed.), Issues in Intimate Violence (pp. 267-284). Thousand Oaks, CA: Sage.

Harlow, L. L., Quina, K., Morokoff, P. J., Rose, J. S., and Grimley, D. M. (1993). HIV risk in women: A multifaceted model. Journal of Applied Biobehavioral Research 1: 3-38.

Harris, S. (1996). For better or for worse: Spouse abuse grown old. Journal of Elder Abuse and Neglect 8(1): 1-33.

Ickovics, J., \& Yoshikawa, H. (1998). Preventive interventions to reduce heterosexual HIV risk for women: Current perspectives, future directions. [Review]. AIDS 12(supplement A): S197-208.

Jemmott, L. S., \& Jemmott, J. B., III. (1991). Applying the theory of reasoned action to AIDS risk behavior: Condom use among black women. Nursing Research 40(4): 228-234.

Kaveny, M. (1998). Older women and health care. America 179(6): 15-19.

Kaye, R., \& Markus, T. (1997). AIDS teaching should not be limited to the young. USA Today, 126(2628): 50-52.

Kelly, J., St. Lawrence, J., Hood, H., \& Brasfield, T. (1989). Behavioral intervention to reduce AIDS risk activities. Journal of Consulting and Clinical Psychology 57: 60-67.

Levy, J. (1998). AIDS and injecting drug use later in life. Research on Aging 20(6): 776-797.

McCandless, N., \& Conner, F. (1999). Older women and the health care system: A time for change. Journal of Women \& Aging 11(2/3): 13-27.

Misovich, S., Fisher, J., \& Fisher, W. (1997). Close relationships and HIV risk behavior: Evidence and possible underlying processes. Review of General Psychology 1: $72-107$.

Neighbors, H. W., Jackson, J. S., Broman, C., \& Thompson, E. (1996). Racism and the mental health of African Americans: The role of self and system blame. Ethnicity and Disease 6(1-2): 167-175.

New York City Department of Health. (2000). Estimates of persons living with AIDS in New York City. New York, NY: Office of AIDS Surveillance.

O'Leary, A., \& Wingood, G. (2000). Interventions for sexually active heterosexual women. In J. Peterson \& R. DiClemente (Eds.), Handbook of HIV prevention (pp. 179-197). New York: Kluwer Academic/Plenum Publishers.

Ory, M., \& Mack, K. (1998). Middle-aged and older people with AIDS: Trends in national surveillance rates, transmission routes, and risk factors. Research on Aging 20(6): 653-664. 
Ory, M., Zablotsky, D., \& Crystal, S. (1998). HIV/AIDS and aging: Identifying a prevention research and care agenda. Research on Aging 20(6): 637-652.

Peacock, P. (1998). Marital rape. In R. Kennedy Bergen (Ed.), Issues in intimate violence (pp. 225-235). Thousand Oaks, CA: Sage Publications.

Penhale, B. (1999). Bruises on the soul: Older women, domestic violence, and elder abuse. Journal of Elder Abuse and Neglect 11(1): 1-22.

Pillemer, K., \& Finkelhor, D. (1989). Causes of elder abuse: Caregiver stress versus problem relatives. American Journal of Orthopsychiatry 59(2): 179-187.

Plichta, S. B., \& Abraham, C. (1996). Violence and gynecological health in women $<50$ years old. American Journal of Obstetrics and Gynecology, 174, 903-907.

Quina, K., Harlow, L., Morokoff, P., \& Saxon, S. (1997). Interpersonal power and women's HIV risk. In N. Goldstein \& J. Manlowe (Eds.), The gender politics of HIV/AIDS in women (pp. 188-201). New York: New York University Press.

Ramsey-Klawsnik, H. (1991). Elder sexual abuse: Preliminary findings. Journal of Elder Abuse and Neglect 3(3): 73-90.

Richard, A. J., Bell, D. C., \& Montoya, I. D. (2000). Age and HIV risk in a national sample of injection drug and crack cocaine users. Substance Use \& Misuse 35(10): 1385-1404.

Rothenberg, K. H., \& Paskey, S. J. (1995). The risk of domestic violence and women with HIV infection: Implications for partner notification, public policy and the law. American Journal of Public Health 85(11): 1569-1575.

Schable, B., Chu, S., \& Diaz, T. (1996). Characteristics of women 50 years of age or older with heterosexually acquired AIDS. American Journal of Public Health 86(11): 1616-1618.

Schaffer, J. (1999). Older and isolated women and domestic violence project. Journal of Elder Abuse \& Neglect, 11(1), 59-77.

Seaver, C. (1996). Muted lives: Older battered women. Journal of Elder Abuse and Neglect 8(2): 3-21.

Semaan, S., Lauby, J., \& Walls, C. (1997). Condom use with main partners by sterilized and non-sterilized women. Women and Health 25(2): 65-85.

Siegal, D., \& Burke, C. (1997). Midlife and older women and HIV/AIDS: My (grand)mother wouldn't do that. In N. Goldstein \& J. Manlowe (Eds.), The gender politics of HIV/AIDS in women (pp. 156-167). New York: New York University Press.

Stall, R., \& Catania, J. (1994). AIDS risk behaviors among late middle-aged and elderly Americans: The national AIDS behavioral surveys. Archives of Internal Medicine 154: 57-63.

Straus, M., Hamby, S. L., Boney-McCoy, S., \& Sugarman, D. B. (1996). The Revised Conflict Tactics Scales (CTS2): Development and preliminary psychometric data. Journal of Family Issues 17(3): 283-316.

Strombeck, R., \& Levy, J. (1998). Educational strategies and interventions targeting adults age 50 and older for HIV/AIDS prevention. Research on Aging, 20(6), 912-936.

Tabnack, F., \& Sun, R. (2000). Need for HIV/AIDS early identification and preventive measures among middle-aged and elderly women. American Journal of Public Health 90(2): 287-288. 
Van der Straten, A., King, R., Grinstead, O., Serufilira, A., \& Allen, S. (1995). Couple communication, sexual coercion and HIV risk reduction in Kigali, Rwanda. AIDS 9: 935-944.

Vinton, L. (1991). Abused older women: Battered women or abused elders? Journal of Women and Aging 3(3): 5-19.

Vinton, L. (1992). Battered women's shelters and older women: The Florida experience. Journal of Family Violence 7(1): 63-72.

Vogler, M., Dugan, T., \& Seidlin, M. (1989, June). Changes in sexual and reproductive behavior in heterosexual couples after HIV testing. Abstract TAP 101 p. 115 presented at the Fifth International Conference on AIDS, Montreal.

Wingood, G., \& DiClemente, R. (1997). The effects of an abusive primary partner on the condom use and sexual negotiation practices of African-American women. American Journal of Public Health 87(6): 1016-1018.

Wolkenstein, B., \& Sterman, L. (1998). Unmet needs of older women in a clinic population: The discovery of a possible long-term sequelae of domestic violence. Professional Psychology: Research and Practice 29(4): 341-348.

Wutoh, A., Hidalgo, J., Rhee, W., \& Bareta, J. (1998). A characterization of older AIDS patients in Maryland. Journal of the National Medical Association 90: 369-373.

Wyatt, G. E., Myers, H. F., Williams, J. K., Kitchen, C. R., Loeb, T., Carmona, J. V., Wyatt, L. E., Chin, D., \& Presley, N. (2002). Does a history of trauma contribute to HIV risk for women of color? Implications for prevention and policy. American Journal of Public Health 92(4): 660-665.

Zablotsky, D. (1998). Overlooked, ignored, and forgotten: Older women at risk for HIV infection and AIDS. Research on Aging 20(6): 760-775. 